\title{
TTF

\section{Exploring how psychosocial factors influence the skill refinement process in tennis}

\author{
John Toner (GBR) and Adam R. Nicholls (GBR)
}

ITF Coaching and Sport Science Review 2016; 70 (24): 22 - 24

\begin{abstract}
Coaches overseeing technical changes, which are driven by the desire to enhance performance, are a very common part of the coaching process among tennis players. $A$ number of psychosocial concomitants (e.g. confidence) appear important in influencing an athlete/coach's ability to successfully implement such refinements. The current study explored this issue by conducting a series of semi-structured interviews with highlyskilled tennis players who have attempted to extensively refine an aspect of their technique. Remaining confident and committed to the changes prescribed by their coach were more likely to make refinement successful. Our data suggests the need for better communication between the coach and athlete at the initiation of the refinement and throughout the process.
\end{abstract}

Key words: Commitment, confidence, expertise, Five-A Model, sports coaching Received: 02 July 2016 Accepted: 03 October 2016 Corresponding author: John Toner

Email: John.toner@hull.ac.uk

\section{INTRODUCTION}

Highly-skilled performers may seek to seek to refine their technique when their movements have become 'attenuated' or when changes in equipment design requires them to find optimal solutions to new problems (Carson \& Collins, 2011; Toner \& Moran, 2015). Despite its apparent ubiquity there has been no systematic study of the psychosocial factors (i.e., mental states, psychological traits, and aspects of the social environment) that might underpin successful or unsuccessful cases of this process. This is surprising given the importance attributed to these factors in helping athletes to address the challenges (i.e., improving their game, recovering from injury, transitioning between sports) that inevitably arise in longitudinal sporting involvement (MacNamara, Button, \& Collins, 2010). In seeking to address this issue, Carson and Collins (2011) proposed four psychosocial factors that influence the process of making technical refinements: involvement in the process, commitment, trust, and confidence in the specific technical refinement prescribed by a coach. We explored Carson and Collins' (2011) proposal by conducting a series of semi-structured interviews with skilled tennis players who have attempted to extensively refine an aspect of their technique.

\begin{tabular}{lcl} 
Pseudonym & $\begin{array}{c}\text { Age and rating when } \\
\text { refinement was made }\end{array}$ & \multicolumn{1}{c}{ Technical refinement } \\
\hline Scott & $16(3.1)$ & Shorten forehand takeback \\
John & $17(2.1)$ & Adopting 'eastern' grip on forehand \\
Mike & $15(3.1)$ & Shorten backhand takeback \\
Matty & $18(3.1)$ & Shorten forehand takeback \\
Paul & $18(1.2)$ & Adopting 'continental' grip on forehand \\
Luke & $28(1.1)$ & Alter forehand path \\
Michelle & $21(2.2)$ & Shorten backhand takeback \\
Andrea & $20(3.1)$ & Square racket face on forehand \\
\hline
\end{tabular}

Note: For junior and adult players there are 20 rating bands, starting with 10.2, which is the lowest, progressing to 10.1, 9.2, 9.1 etc. until you reach 1.1, which is the highest rating.
Six males and two females aged between $19-30$ years (Mage $=$ $23.5, S D=4.3$ ) with experience of refining their technique within the last 5 years were purposively recruited for this study (see Table 1 for details).

Each participant took part in an in-depth, face-to-face semistructured interview. Although interview topics and supplementary probes were informed by the work of scholars in the field of technical refinement (e.g. Carson \& Collins, 2011), the semi-structured nature of encouraging elaboration and seeking clarification within the interviews ensured flexibility and sensitivity toward emergent issues. Interviews lasted between $55-95 \quad$ minutes.

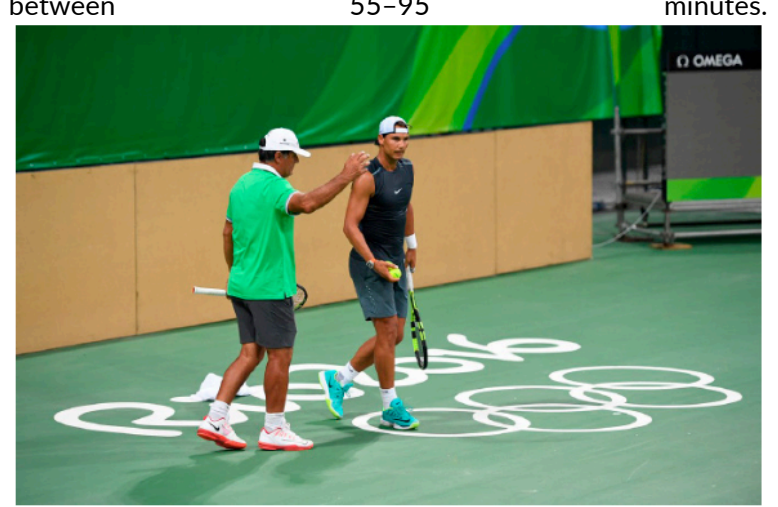

The main focus of the interviews was on identifying the moderators of change (i.e. the psychosocial factors that influenced the refinement process).

\section{ANALYSIS}

Data was analysed abductively (i.e. involving a succession of inductive and deductive processes). Inductive content analysis was used to identify meaning units which were subsequently grouped together to form emergent categories (lower-order themes) based on their similarity to each other and distinction from other categories. This process was then repeated in order to generate higher-order themes until theoretical saturation was reached, whereby all new meaning units fitted into the existing code structure. 


\section{RESULTS}

In this section we outline two key psychosocial moderators (i.e. commitment and confidence) that influenced the extent to which the technical refinement process was successful or unsuccessful.

\section{Commitment}

Players discussed their level of commitment to executing the desired technique, particularly during the early stages of making the change. They revealed that they felt uncomfortable with the movement when they first tried it in a competitive situation and this resulted in a lack of commitment to selecting the effected shot. Although all of the participants were fully committed to the new movement in practice, this changed when some of them played in a competitive event.

Here their competitive urge to win appeared to override their desire to remain committed to trying the new movement. For example, Scott explained that he:

was sticking to the shape, but it's almost the competitive side of you.... I wanted to win too much to be able to just to stay with it and accept a few errors.../ stuck with the new movement when I hit a top-spin forehand, but I wouldn't say that I hit that many of them as I was trying to avoid hitting it.

Athletes' commitment was also influenced by the extent to which they were prepared to accept that they would make errors during competition. John suggested that he may have struggled to adopt the technique because he put himself under so much pressure to execute it flawlessly - even during the initial stages of the change:

I wasn't prepared to make even one forehand error... I created that mindset for myself where I wasn't allowed to make mistakes and to fail with it . . I I created a fear of making mistakes and a fear of losing.

Although the preceding evidence would suggest that a number of players struggled to commit to the new movement, four players revealed that, despite initial setbacks in competition, they steadfastly committed to the new technique because they realized that there was no reason to go back to the old inefficient movement pattern. To illustrate, Mike was prepared to accept that he would "hit a lot of errors. ... In my head I knew that I was better going for it and making the error than just running around it or hitting a slice and winning". These players also spoke about the important role their coaches played in removing pressure by emphasizing that practice and competitive results were not important in the early stages of the change process (i.e., focusing on the processes of performance). Matty revealed that he was worried that he was going to lose matches during the initial stages of the change, but:

In that month I had two tournaments that I went out of first round... coach was like 'don't worry about winning just go out and try to get the technique'. . . he was like 'when you're changing something new expect to lose but you'll start winning again once you get it correct'.

The extent to which these players regulated their expectations is in notable contrast to the experiences of both John and Paul (who struggled with their change) who reported putting themselves under considerable pressure from the start. For example, Paul revealed that his attitude was "can we get this done as quickly as possible ... so maybe progressing it a bit too quick so I hadn't built the foundation - so the hand feed I hadn't really perfected that and we're trying to rush it because I was still competing in competitions".

\section{Confidence}

Confidence also had an important bearing on players' ability to successfully enact change. Six players reported high confidence in their coaches' ability to help them improve their game. Scott recalled when the idea was introduced to him that he felt:

pretty confident, I was just so happy with my tennis at the time and again because of the two people working with me I was like for sure this is going to work... it's not going to [negatively] affect me.

Early setbacks in competitive events had a significant impact on four players' confidence in their ability to execute the new technique under pressurized conditions. For example, John explained that:

there had been an overall dent in my morale because of the way the tournament went and looking back that would have resulted in my training attitude being low. . . it was quite demoralising really... I was thinking it couldn't have gone any better in practice the day before the tournament and I still couldn't do it so my confidence in it and my enjoyment of doing it would have been less in subsequent weeks.

Significantly, the players who retained confidence in their own ability to execute the new movement under pressurized conditions were working with coaches who appeared to have used a variety of

psychological skills to develop their confidence. For example, these coaches attempted to get five players to focus on the processes of the performance rather than on the outcome of a competition. In three cases, coaches appeared to use reframing/restructuring by showing the athlete evidence of successful performances on a tablet device or video recorder. Andrea felt that seeing 'good' performances on video made it "clear in her mind what I was doing and what I was aiming for" and that this enhanced her confidence that her action was improving in the desired direction.

\section{DISCUSSION}

The results demonstrate that the technical refinement process involves a degree of risk and that cases of unsuccessful change are likely to affect not only an athlete's skill development, but also their long-term involvement in competitive sport. However, it is encouraging to note that four players felt that the process had been extremely successful and that it had contributed to the improvement of their game. Significantly, the results provide empirical support for the FIVE-A model's (Carson \& Collins, 2011) proposal that a number of psychosocial concomitants will have an important bearing on whether or not coaches and players can successfully enact technical change. Retaining the athlete's commitment to, and confidence in the process, seems absolutely crucial in this regard.

Commitment to the new movement may be enhanced if coaches can encourage their players to appropriately regulate their expectations. Players may need to accept that the new movement is likely to feel uncomfortable and that they will experience a drop in performance proficiency for a period of time. In the long-term, the use of imagery scripts and self-set goals may allow coaches to 'sell' progress to the athlete and maintain their commitment to the change. There are also a number of approaches that coaches may employ in seeking to enhance the athlete's confidence in the new movement. Coaches should encourage their athletes to avoid competition until they are confident that they can consistently perform the new movement under pressurized practice conditions (that it is "pressure-proofed"; See Carson \& Collins, 2016). Moreover, it may be wise to initiate the change during the player's 'offseason' rather than in the midst of the competitive season. Confidence profiling techniques may also be used to assess the 
athlete's confidence levels and to generate confidence enhancing strategies targeted toward their perceived confidence needs (Hays, Thomas, Maynard, \& Butt, 2010). Finally, video may be used to enhance the athlete's confidence that they are progressing towards the desired technique. Additionally, coaches could adopt an autonomy supportive coaching style during the refinement process, which is characterised by the coach listening to his or her player's views, allow them to make an input into the process, and focus on improvement rather than the outcome of matches.

REFERENCES

Carson, H.J., \& Collins, D. (2011). Refining and regaining skills in fixation/diversification stage performers: The Five-A Model. International Review of Sport and Exercise Psychology, 4, 146167.https://doi.org/10.1080/1750984X.2011.613 682

Carson, H.J., \& Collins, D. (2016). Implementing the Five-A Model of technical refinement: Key roles of the sport psychologist. Journal of Applied Sport Psychology. 28,

392-

409.https://doi.org/10.1080/10413200.2016.1162 224

Hays, K., Thomas, O., Maynard, I., \& Butt, J. (2010). The role of confidence profiling in cognitive-behavioral interventions in sport. Sport Psychologist, 24, 393.https://doi.org/10.1123/tsp.24.3.393

MacNamara, Á., Button, A., \& Collins, D. (2010). The role of psychological characteristics in facilitating the pathway to elite performance. Part 2: Examining environmental and stage-related differences in skills and behaviors. The Sport Psychologist, 24, 7496.https://doi.org/10.1123/tsp.24.1.74

Toner, J., \& Moran, A. (2015). Enhancing performance proficiency at the expert level: Considering the role of 'somaesthetic awareness'. Psychology of Sport and Exercise, 16, 110117.https://doi.org/10.1016/j.psychsport.2014.07. 006

RECOMMENDED ITF TENNIS ACADEMY CONTENT (CLICK BELOW)

\section{ITF Academy}

Copyright (c) John Toner and Adam R.Nicholls 2016

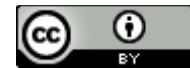

This text is under a Creative Commons BY 4.0 license

You are free to Share - copy and redistribute the material in any medium or format - and Adapt the content - remix, transform, and build upon the material for any purpose, even commercially under the following terms:

Attribution: You must give appropriate credit, provide a link to the license, and indicate if changes were made. You may do so in any reasonable manner, but not in any way that suggests the licensor endorses you or your use.

CCBY 4.0 license terms summary $\quad$ CC BY 4.0 license terms 